\title{
Exercises in Human Imagination
}

\section{J. T. Trevors • M. H. Saier Jr.}

Published online: 9 December 2006

(C) Springer Science + Business Media B.V. 2006

Exercising our imaginations yields powerful and rewarding advances. For example, it allows us to paint magnificent works of art, create sculptures, write fiction, manufacture goods, design services and undertake creative, scientific research. It has allowed the development of medical knowledge, reducing the suffering caused by diseases and increasing the human life span. It has permitted us to communicate with others thousands of miles away in just seconds. Imagination has also allowed humankind to explore the physical universe, unlocking its mysteries by way of space travel and the Hubbell telescope, and revealing the awe-inspiring, immensity and beauty of the universe. Without imagination and the world of ideas, human societies would not have evolved to their present states of complexity. No other species on the planet has as much imagination as do humans, and consequently, no other species has developed as complex a knowledge base or as elaborate a set of communication systems.

\section{J. T. Trevors}

Department of Environmental Biology,

University of Guelph,

Guelph, ON, Canada N1G 2W1

M. H. Saier Jr. $(\bowtie)$

Division of Biological Sciences, University of California, San Diego, La Jolla, CA 92093-0116, USA

e-mail: msaier@ucsd.edu
Human beings, and many other animals, can predict outcomes before they occur. However, the extent to which this is possible by man far exceeds that achievable by other animals. This is because only we have developed and applied scientific methods to an understanding of the natural world. Other animals may know that an object released from our hands will fall downward and strike the floor, but only we understand the gravitational basis for this action. Additionally, while animals can remember their experiences of the past and modify their behavior accordingly, only we can learn from the experiences of previous generations and other people living far from us.

We are just beginning to understand how our minds, memories and imaginations function. Surprises and research breakthroughs will come in the future, and these often result from intuitive insights into matters of scientific importance. However, unquestionably, imagination without systematic examination can lead us astray and guide us into activities that harm humanity. What are some examples of the use of imagination that led mankind to erroneous conclusions?

Humans once believed that the Earth was flat; they were wrong. They once believed the Earth was at the center of the universe; again they were wrong. The Ancient Greeks imagined that earthquakes were caused by the anger of Poseidon, and lightening represented the anger of Zeus. They too were wrong. 
The ancient Greeks also thought there were four elements - water, fire, air and earth, but they were wrong. In those days, humans had no concept of the atomic nature of matter, although no one now questions the relevant scientific evidence. Most people once believed that disease and pestilence resulted from acts of supernatural beings; they too were wrong. They had no inkling that microscopic organisms cause diseases. This state of ignorance was changed with the invention of the microscope.

Is religion, the belief in a supernatural world, merely an exercise in human imagination, or is it a faith-dependent, intuitive perception of an existence beyond our mental capabilities? Regardless of the answer to this question, some people imagine a place that is better than our own world, and consequently, they don't take responsibility for conditions on Earth. Does the expectation of an afterlife, reincarnation or an eternally exalted mental state diminish the desire to maintain the here and now? The mythical place called heaven may have been invented to provide hope for eternal continuity; or heaven and hell may have been invented to aid in the maintenance of social order. The possibility of a reward or a punishment in an afterlife, may provide comfort and reassurance to some; such a belief must have its personal benefits, but it may also be a form of delusion which allows people to neglect their responsibilities to others on Earth. It may deter us from facing reality.

Can we imagine the direction the quality of life is likely to take as the human population increases and limited resources dwindle while we continue to pollute the earth? More demands will be placed upon potable water, food, energy and social infrastructures for transportation, education, health care and security. If humans have such powerful imaginations, why is it that this process of extrapolation is so difficult to conduct? Why are correct actions not implemented to ensure the future of humanity in our common biosphere? With billions of more people added to the present 6.5 billion, it does not take much imagination to predict the outcome.

Many people today seem to believe that future generations will live better than we do. However, most projections suggest that conditions will deteriorate. Even today, with our current population, hundreds of millions of people are without the basic necessities of life. The human imagination is powerful enough, if used correctly, to project and then manage the common biosphere with minimal pollution and waste as well as maximal benefit to a majority of humans and other species. Such management requires above all limiting human fertility.

To those people who do not believe in or imagine a place such as heaven, there is still humanity, the biosphere and the universe. We can value the sanctity of life, all life, as we know it, and imagine the existence of life elsewhere in the universe. We have no scientific evidence of a God or Gods, of heaven or hell, of eternal life, of reincarnation or of an enlightened state that persists after death. Maybe we should live life as though this is the only one we have! Even if we do so, we can hope for more without distorting reality, turning to mysticism, and neglecting responsibility.

We believe that mankind should use its imagination as a guide for the pursuit of truth and the betterment of humanity. We can envision a common sustainable future on Earth with only the number of humans the planet can sustain with quality life. And, given skilled, knowledgeable leadership, this goal would not be difficult to achieve! But without this leadership, Darwinian natural selection will promote the much-feared state of human suffering, a state of "hell on Earth," a state no one wants to endure, a state no one should want to inflict on others. 